\title{
Postnatal testicular development in mouse species with different levels of sperm competition
}

\author{
Laura Gómez Montoto, Lucía Arregui, Noemí Medina Sánchez, Montserrat Gomendio and \\ Eduardo R S Roldan \\ Reproductive Ecology and Biology Group, Museo Nacional de Ciencias Naturales (CSIC), c/Jose Gutierrez Abascal 2, \\ 28006 Madrid, Spain \\ Correspondence should be addressed to ER S Roldan; Email: roldane@mncn.csic.es
}

L Arregui is now at Department of Biology, Universidad Autónoma de Madrid, Madrid, Spain

\begin{abstract}
Postcopulatory sexual selection leads to an increase in sperm numbers which is partly the result of an increase in relative testes mass and could also be the consequence of changes in testis architecture or function. Very little is known regarding developmental changes during the first spermatogenic wave that may lead to enhanced spermatogenic efficiency and increased sperm production. We examined testicular development after birth in four mouse species with different sperm competition levels to assess changes in testicular architecture and function. Differences in relative testes mass between species appeared soon after birth and were exacerbated thereafter. The volume of testes occupied by seminiferous tubules differed between species postnatally and were associated with sperm competition levels. Finally, changes over time in the proportions of tubules with different germ cell types were also associated with sperm competition levels, with the time taken for the transition between various cell stages being negatively associated with levels of sperm competition. We conclude that postnatal testis development differs between closely related species with different sperm competition levels influencing testis architecture and the rate of progression of spermatogenesis, leading to differences in testis function at reproductive maturity.

Reproduction (2012) 143 333-346
\end{abstract}

\section{Introduction}

Postcopulatory sexual selection, in the form of sperm competition (Parker 1970), selects for a variety of male reproductive traits (Birkhead et al. 2009), such as ejaculates with increased sperm numbers and quality (Møller 1988, Birkhead et al. 1999, Hunter \& Birkhead 2002, García-González \& Simmons 2005, Firman \& Simmons 2010, Gómez Montoto et al. 2011), as well as longer spermatozoa that perform better (Gomendio \& Roldan 1991, 2008, Gomendio et al. 2007, 2011, Fitzpatrick et al. 2009, Lüpold et al. 2009a, Tourmente et al. 2011a, 2011b). Males that produce more spermatozoa are more likely to father offspring under conditions of sperm competition because the number of sperm is a key determinant of fertilization success (Birkhead \& Møller 1998, and references therein). An increase in sperm output and more sperm cells per ejaculate are thus widespread responses to enhanced sperm competition levels (Gomendio et al. 1998).

Higher sperm numbers can be produced by a variety of mechanisms. An increase in testes mass relative to body mass is a general response in many taxa (Harcourt et al. 1981, Hosken 1997, 1998, Stockley et al. 1997,
Gomendio et al. 1998, Hosken \& Ward 2001, Pitnick et al. 2001, Simmons 2001, Byrne et al. 2002, Birkhead et al. 2009). Larger testes produce more sperm, as revealed by increases in both sperm reserves in the epididymides and sperm numbers per ejaculate (Møller 1988, 1989, Gómez Montoto et al. 2011). A higher relative testes mass associates significantly with a percentage of multiple paternity (Firman \& Simmons 2008, Soulsbury 2010) and, thus, relative testes mass has been used as a proxy of sperm competition levels.

Other mechanisms increasing sperm production and contributing to higher sperm output have been identified. Changes in testicular architecture may result in more sperm-producing machinery. Among primates, species with relatively larger testes have a greater proportion of seminiferous tubules than species with lower relative testes mass (Schultz 1938) and, in the great apes, the proportion of seminiferous tubules varies in agreement with relative testes mass being highest in the chimpanzee and lowest in the gorilla (Fujii-Hanamoto et al. 2011). Among rodents, the proportion of testicular volume occupied by seminiferous tubules was greater in Pseudomys australis (the Plains Rat), a species with high relative testes mass, than in Notomys alexis the Spinifex 
Hopping Mouse, which has a low relative testes mass (Breed 1982, Peirce \& Breed 1987, 1990). Furthermore, in comparative studies in birds, species with higher combined testes mass in relation to body mass exhibited an increase in the proportion of seminiferous tissue (Lüpold et al. 2009b, Rowe \& Pruett-Jones 2011). Therefore, available evidence suggests that increases in the levels of sperm competition are associated with a higher proportion of seminiferous tubules which may, in turn, explain higher sperm output.

More spermatozoa may also be generated by modifications of testicular function resulting in a more efficient machinery. Among others, changes may include faster turnover of the sperm production cycle (Ramm \& Stockley 2010), higher numbers of cell divisions during the proliferative, premeiotic phase (Ehmcke et al. 2006), or modifications in the relationship between germ cell proliferation, loss, and survival (Hess \& França 2008).

Spermatozoa are produced in the seminiferous tubule compartment of the testes in a process known as spermatogenesis. The tubules are lined by the seminiferous epithelium, which consists of germ cells and Sertoli cells, with the latter supporting and nourishing the germinal epithelium. A lumen occupies the centre of the tubule to which the mature sperm cells are released. The space between the seminiferous tubules, referred to as the interstitial tissue, contains Leydig cells (which produce male sex hormones), blood and lymphatic vessels, and macrophages (Setchell \& Breed 2006). The germ cells in the seminiferous epithelium go through three phases: proliferation, chromosome reduction (meiosis), and differentiation (spermiogenesis) (Clermont 1972, Russell et al. 1990, Kerr et al. 2006, Hess \& França 2008, Hermo et al. 2010). The length of each of these phases is about one-third of the total process of spermatogenesis, and the total duration of spermatogenesis varies between species (Johnson 1995, 2000, Kerr et al. 2006); the length of spermatogenesis appears to be controlled by the genotype of the germ cells (Zeng et al. 2006, Arregui et al. 2008).

The cells that divide by mitosis during proliferation and constitute the group of cells from which meiosis and spermiogenesis proceed are termed spermatogonia; they thus constitute the stem cells for spermatogenesis (De Rooij \& Russell 2000). Type A spermatogonia divide by mitosis to replace themselves and to provide a population of type In spermatogonia which, in turn, differentiate into type B spermatogonia from which primary spermatocytes arise (Kerr et al. 2006, Borg et al. 2010). Germ cells undergoing meiosis are the primary and secondary spermatocytes and completion of meiosis gives rise to haploid round spermatids that undergo a series of morphological changes with no cell division involved. Spermatids experience elongation during a series of developmental steps that include changes in cellular organelles such as acrosome formation, nuclear reshaping and condensation, development of the flagellum, reorganization and elimination of cytoplasm, and final release to the lumen of the seminiferous tubule during spermiation (Kerr et al. 2006, Tanaka et al. 2007).

The morphology and function of the testis that is observed in adult males develops during a protracted period of time before and during puberty (Kerr et al. 2006). Primordial germ cells first appear during foetal development. They proliferate, migrate, and establish the gonadal primordium. Nonmigrating germ cells in the gonad are called gonocytes and they arrest proliferation until around puberty. A series of cues trigger resumption of proliferation and the first spermatogenic wave begins. There are important differences between primates and most rodents because in the former there is a clear period of separation between postnatal and pubertal period, whereas this is not the case in the mouse and other rodents. In primates, spermatogenesis starts many months or years after birth, but in rodents it begins within a few days after birth. In the laboratory mouse, the first wave of spermatogenesis encompasses the proliferation and differentiation of germ cells and Sertoli cells over a period of 35 days, full fertility is reached by $6-7$ weeks of age, and key time points for the appearance of particular types of germ cells are well defined (Bellvé et al. 1977, Bellvé 1993, Borg et al. 2010).

Studies of postnatal testis development have allowed a characterization of the first spermatogenic wave. A complex interaction between circulating folliclestimulating hormone (FSH) and local testicular factors including activin and inhibin, and their effects on germ cell differentiation, was revealed during this first wave (Barakat et al. 2008, Mithraprabhu et al. 2010). Partial synchronization of spermatogenesis in some species has also been identified (Van Haaster \& De Rooij 1994). Furthermore, germ cell apoptosis and underlying molecular mechanisms were also characterized in this first round of spermatogenesis (Jahnukainen et al. 2004). Expression of testicular germ cell genes during specific stages of spermatogenesis has also been assessed during postnatal development (Lahn et al. 2002, Anway et al. 2003, Wrobel \& Primig 2005, Hansen et al. 2006, Cao et al. 2008, Itman \& Loveland 2008, Albert et al. 2010). Finally, stages of postnatal development have been examined with the aim of identifying reproductive isolation in hybrid mice due to spermatogenic defects at several stages (Oka et al. 2010). Therefore, the first spermatogenic wave represents an important tool for the timing and characterization of cellular and molecular events during spermatogenesis, because it is possible to identify the progression through different cell types as they appear for the first time. Thus, the first spermatogenic wave is regarded as a useful model to study spermatogenesis.

In this study we have examined, using four closely related murid species that differ in sperm competition levels (Gomendio et al. 2006), if this selective force exerts an influence on the postnatal development of 
testes architecture and turnover of germinal epithelium which may explain differences in sperm production. In addition, the study of postnatal development allowed us to understand when and how differences in testes architecture and function originate.

\section{Results}

\section{Body mass and testes mass}

Changes in body mass during postnatal growth differed between the four mouse species $\left(F_{3,84}=56.20\right.$, $P<0.001$; Fig. 1A). Although they experienced a similar increase in body mass until 14 days after birth, from 20 days onwards the species started to differ. Significant differences in body mass were observed in adult mice (120 days old; $F_{3,20}=45.36, P<0.001$ ).

Testes mass increased during postnatal growth and differed between species $\left(F_{3,84}=240.36, P<0.001\right.$; Fig. 1B) and Bonferroni's post-hoc tests showed that there were significant differences between the four mouse species throughout postnatal development. From an early age (10 days), testes masses of Mus spretus and Mus spicilegus were higher than those of Mus musculus and Mus pahari and from 24 days onwards $\left(F_{3,8}=25.87, P<0.001\right)$ these two sets of species (M. spretus-M. spicilegus and M. musculus-M. pahari) differed significantly in testes mass. Adult testes mass of the four species were significantly different at 120 days postpartum $\left(F_{3,20}=170.77, P<0.001\right)$.

As a consequence of differences in body and testes masses, relative testes mass differed between species revealing ample variation in the levels of sperm competition among them (Fig. 1C). M. spicilegus showed the highest values of relative testes mass from 6 days to adulthood, followed by M. spretus (which had highintermediate values), M. musculus (with low-intermediate values) and, finally, M. pahari, with the lowest relative testes mass throughout the period examined.

\section{Absolute measures and proportions of seminiferous tubules}

Different measures were obtained from seminiferous tubule cross-sections (Fig. 2). From birth to sexual maturity, all the components of the seminiferous tubules increased significantly in size. Most measures differed significantly between species throughout postnatal development. Thus, the seminiferous tubule crosssectional area $\left(F_{3,84}=29.26, P<0.001\right.$; Fig. $\left.3 \mathrm{~A}\right)$, seminiferous epithelium heigh $\mathrm{t}\left(F_{3,84}=43.29, P<0.001\right.$; Fig. $3 \mathrm{~B})$, and seminiferous epithelium area $\left(F_{3,84}=51.22\right.$, $P<0.001$; Fig. 3D) were different between mouse species, whereas no significant differences were seen in lumen area (Fig. 3C). Post-hoc analyses revealed that, with the exception of the lumen area, there were clear differences between all four species in absolute measures
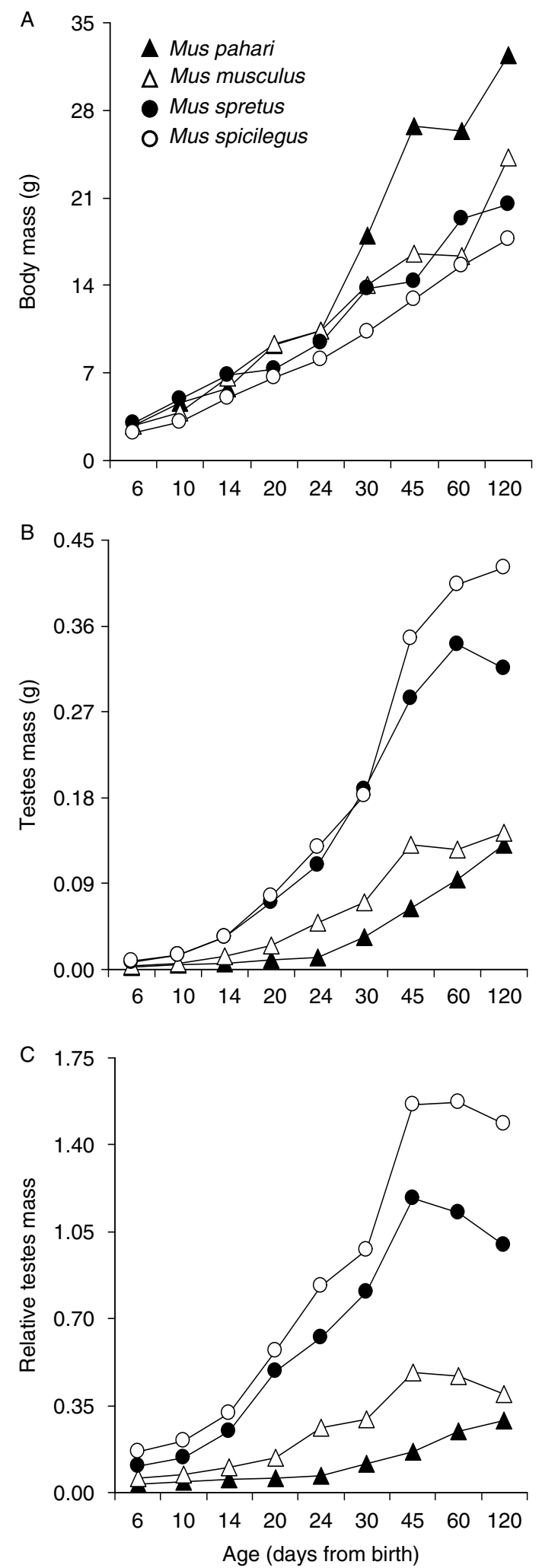

Figure 1 Changes in (A) body mass, (B) testes mass, and (C) relative testes mass from 6 to 120 days after birth in four mouse species (Mus. pahari, Mus. musculus, M. spretus, and M. spicilegus). 


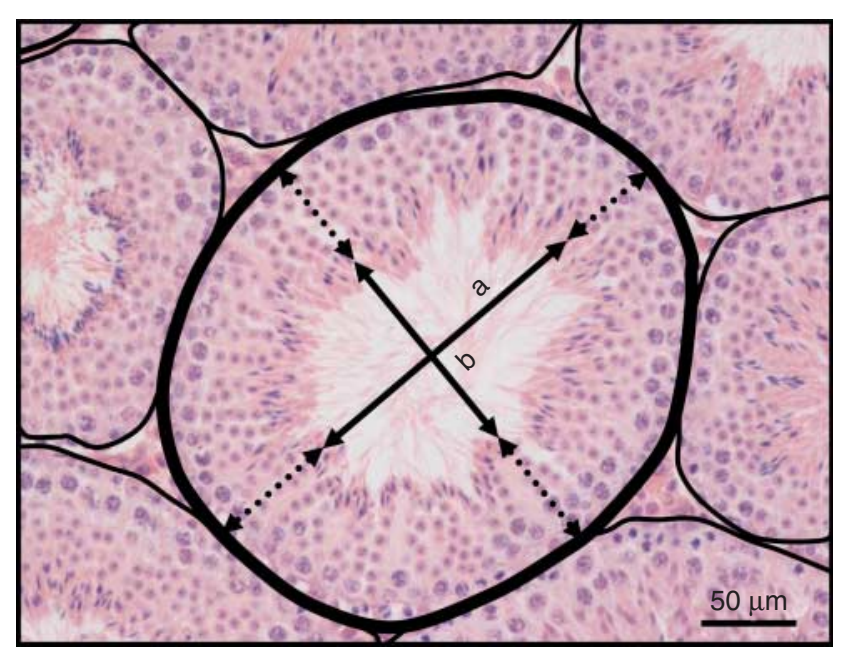

Figure 2 Measurements of components of the seminiferous tubules and the proportion of seminiferous tubules and interstitial tissue. The mouse testis section shows how measures of seminiferous tubules were taken. The thick line delineates the circumference of the seminiferous tubule used to determine the total seminiferous tubule cross-sectional area.

The double-headed arrows (dotted lines) show the seminiferous epithelium height. The double-headed arrows (continuous line) indicate the length and width of the lumen, where ' $a$ ' is the major axis and ' $b$ ' is the minor axis. The percentage of total seminiferous tubules in the testis was obtained by measuring the area occupied by the tubules (delineating the circumference of all the tubules in an image; narrow and thick lines), whereas the percentage of interstitial tissue was calculated by subtracting the area occupied by the seminiferous tubules from the total area of the image.

of tubule size. In adult mice, the seminiferous tubule cross-sectional area $\left(F_{3,20}=9.63, P<0.001\right)$ and the seminiferous epithelium area $\left(F_{3,20}=10.16, P<0.001\right)$ were significantly higher in $M$. musculus than in $M$. spicilegus, whereas seminiferous epithelium height was higher in $M$. spretus than in $M$. spicilegus $\left(F_{3,20}=5.18\right.$, $P=0.008$ ). Overall, the main differences between species in tubule cross-sectional area, epithelium height, and epithelium area were noted between 20 and 30 days postpartum and some remained thereafter. However, none of these differences exhibited a pattern in agreement with what was expected if they were associated with differences in the levels of sperm competition of these species.

The proportion of total seminiferous tubules and interstitial tissue was calculated at different times after birth (see Fig. 2). The percentage of total seminiferous tubules increased significantly during postnatal development $\left(F_{8,84}=132.60, P<0.001\right)$, with an overall significant difference between species $\left(F_{3,84}=52.96\right.$, $P<0.001$; Fig. 4A). In agreement with this, the percentage of interstitial tissue decreased during postnatal development (Fig. 4B; $F_{8,84}=130.77$, $P<0.001)$. Differences between species showed a wide range of values shortly after birth (at 6 days, the range was $60-80 \%$ seminiferous tubules for the four species), but the range was narrower in adult animals (about
90-95\% for all species). Thus, there was a marked increase in the percentage of seminiferous tubules in $M$. pahari (from $\sim 60$ to $\sim 90 \%$ ) and M. spicilegus (from $\sim 65$ to $\sim 95 \%$ ), with a less pronounced increase in $M$. musculus (from $\sim 75$ to $\sim 90 \%$ ) and M. spretus (from $\sim 80$ to $\sim 95 \%$ ). The differences in increase in percentage of seminiferous tubules between the species did not show any relationship with relative testes mass that would suggest that such increase is directly associated with levels of sperm competition. However, the percentage of seminiferous tubules in adult males showed significant differences $\left(F_{3,20}=26.43, P<0.001\right)$, with two species (M. pahari, M. musculus) having lower values than the two other species (M. spretus, M. spicilegus; Fig. 4A), in agreement with their differences in relative testes mass.

\section{Volumetric measures}

The volume of testes increased from birth to adulthood $\left(F_{8,84}=269.98, P<0.001\right)$ and such an increase varied significantly between species $\left(F_{3,84}=267.69, P<0.001\right)$. The species also had a considerable effect on the volume of testes occupied by seminiferous tubules (Fig. 5A; $\left.F_{3,84}=266.47, P<0.001\right)$, which increased in all species throughout postnatal development $\left(F_{8,84}=267.63\right.$, $P<0.001)$. The volume of testes occupied by seminiferous tubules was consistently lower in $M$. pahari and $M$. musculus than in $M$. spretus and $M$. spicilegus from 10 days onwards $\left(F_{3,8}=23.51, P<0.001\right)$ with the values for M. spicilegus being significantly higher than those for the other species at 45 days postpartum $\left(F_{3,8}=95.88\right.$, $P<0.001)$. Adult males of $M$. pahari and $M$. musculus showed a similar volume of testes occupied by seminiferous tubules, which was significantly lower than that in $M$. spretus which, in turn, was significantly lower than that in $M$. spicilegus $\left(F_{3,20}=197.20\right.$, $P<0.001)$. These differences were associated with the levels of sperm competition in these species.

Relative to body mass, the volume of testes occupied by seminiferous tubules differed widely between species (Fig. 5B), M. spicilegus being the species with the highest values along all of postnatal development, followed, in decreasing order, by $M$. spretus, M. musculus, and $M$. pahari, the species with the lowest relative volume of testes occupied by seminiferous tubules. These results were, again, associated with levels of sperm competition in the four mouse species.

\section{Changes in cell types in seminiferous tubules during postnatal development}

During postnatal testicular development, we quantified the proportion of seminiferous tubules according to the most advanced germ cell stage in each tubule, in an attempt to characterize the first spermatogenic wave (Fig. 6A-I). There were important changes in the 

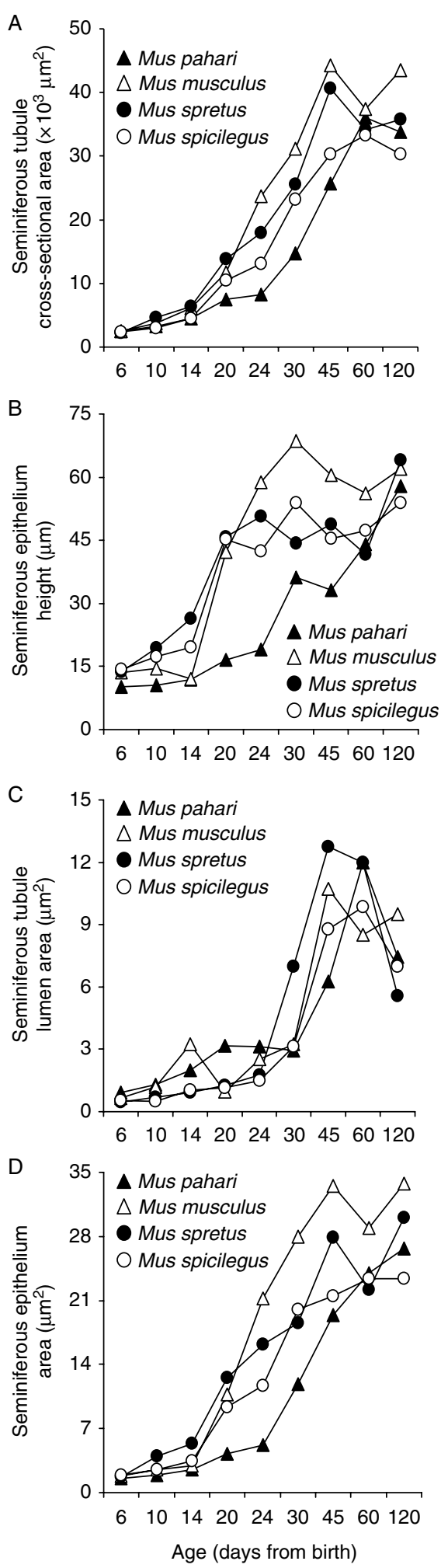

Figure 3 Measures of seminiferous tubules from 6 to 120 days after birth in four mouse species (M. pahari, M. musculus, M. spretus, and M. spicilegus). (A) Seminiferous tubule cross-sectional area. (B) Height of the seminiferous epithelium. (C) Area of the lumen of the seminiferous tubule. (D) Area occupied by the seminiferous epithelium. For details of how measures were taken, see the 'Materials and Methods' section. predominant type of seminiferous tubules from birth to adulthood and clear differences were seen between species with regards to the pattern of predominant seminiferous tubule types.

A comparison between species revealed significant differences in the pattern of cells present in the testes at various time points during postnatal development (Fig. 7A-D). At the earliest time examined (14 days), M. pahari exhibited all seminiferous tubules with only Sertoli cells and spermatogonia, and this was also the predominant seminiferous tubule type of $M$. musculus testes, although some tubules contained spermatocytes. On the other hand, in M. musculus and M. spicilegus, spermatocytes were present in the majority of tubules. At 30 days postpartum, M. pahari exhibited about $30 \%$ of tubules with round spermatids as the most advanced stages, with the majority of tubules containing spermatocytes. In contrast, in M. musculus, the largest proportion of tubules contained round spermatids with about one-third of them already exhibiting spermatids (15\% with elongating spermatids, and another $15 \%$ with elongated spermatids). Furthermore, in M. spretus and M. spicilegus, about half of the tubules contained elongated spermatids. By 45 days, M. pahari still had over $10 \%$ of tubules with spermatocytes as the most advanced stage and a high proportion of tubules ( $30 \%)$ with round spermatids, whereas in the other three species the vast majority of tubules contained elongating and, mainly, elongated spermatids. Finally, no major differences were seen between species in the pattern exhibited at 60 and 120 days postpartum, with the majority of seminiferous tubules containing elongated spermatids (Fig. 7).

A comparison of the progression over time in the proportion of tubules with different cell types showed differences between the species (Fig. 8A-D). Changes in the percentage of seminiferous tubules with Sertoli cells and spermatogonia, the earliest stage recognized, revealed that the decline over time was very fast in M. musculus, M. spretus, and M. spicilegus, whereas the decrease in $M$. pahari was much slower (Fig. 8A). Changes in the proportion of tubules with spermatocytes as the most advanced stage revealed a steep rise followed by a rapid decline in $M$. musculus and M. spicilegus while in M. spretus there was a continuous decline from the time of first sampling, suggesting that the first time point examined was already past the peak in the proportion of seminiferous tubules with spermatocytes; on the other hand, in M. pahari, the increase in percentage of tubules with spermatocytes developed slowly and the decrease was also slow (Fig. 8B). The timing of appearance of a majority of tubules with round spermatids varied between species and the same was observed with the decline in such proportion; however, the pattern (shape) of the curve was similar for most species (with similar time frames), but it was much faster for M. spicilegus with a steeper rise and decline (Fig. 8C). 

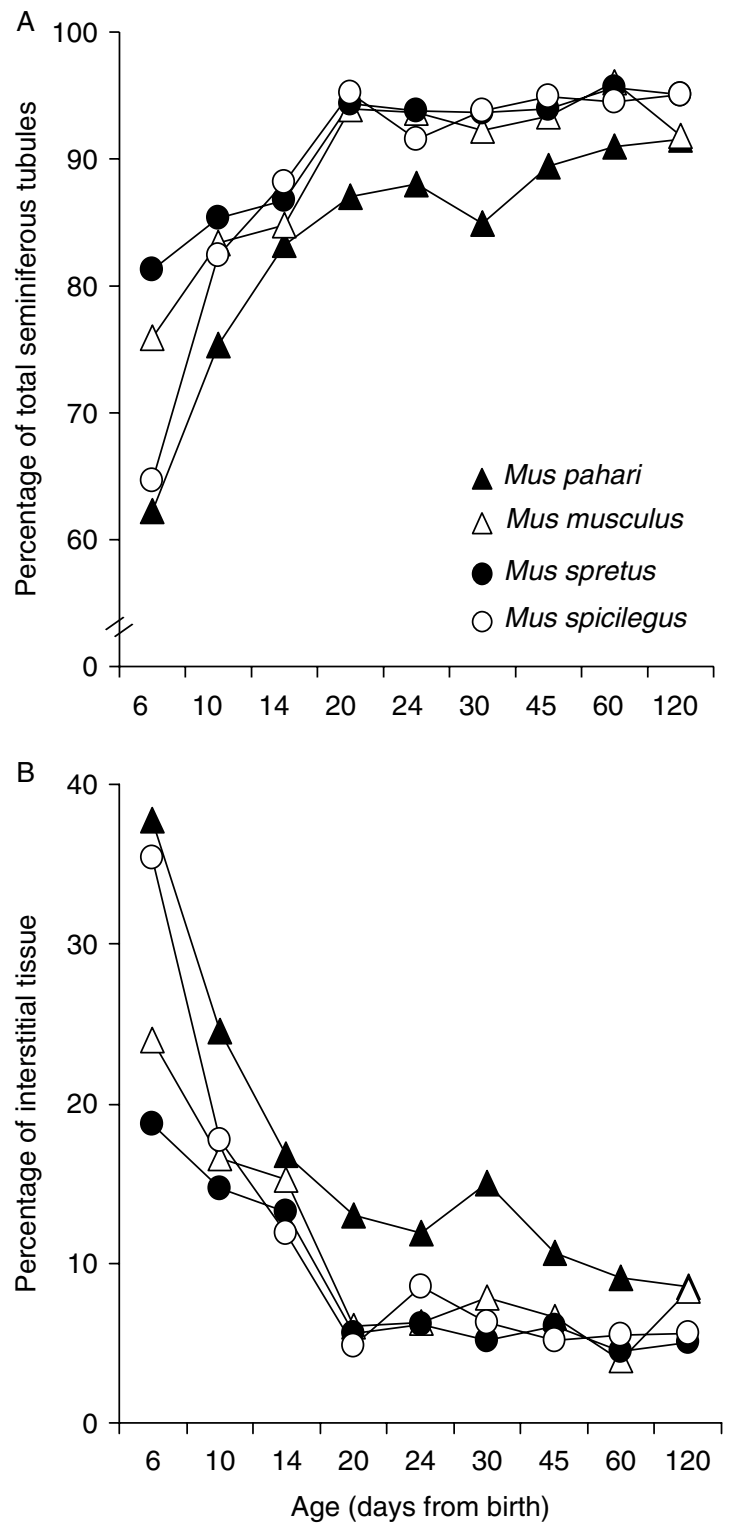

Figure 4 (A) Percentage of total seminiferous tubules and (B) percentage of interstitial tissue in the testes of four mouse species (M. pahari, M. musculus, M. spretus, and M. spicilegus) at different times after birth.

Finally, the rise in the proportion of tubules with differentiating spermatids (i.e. elongating and elongated) followed a sigmoid pattern that was similar for all species with the exception of M. pahari which had a much later start but which then exhibited a similar rate of increase as the other species (Fig. 8D). The proportion of tubules with differentiating spermatids reached a plateau at 45 days postpartum in three species (M. musculus, M. spretus, and M. spicilegus) and only at 60 days in the remaining one (M. pahari).

Based on the changes described above, we estimated the time taken for each species to undergo the transition between several stages, namely from spermatocyte (i.e. the beginning of meiosis) to round spermatids (the end of meiosis), and elongating and elongated spermatids (i.e. the completion of spermiogenesis), and the overall transition from spermatocytes to elongated spermatids. We found that M. pahari and M. musculus had a transition time from spermatocytes to elongated spermatids of 36 and 40 days respectively, whereas the estimated transition times of $M$. spretus and M. spicilegus were 31 and 25 days respectively (Fig. 9). Thus, species with higher levels of sperm competition have faster transition times from spermatocytes to elongated spermatids.

\section{Discussion}

The results of this study suggest that sperm competition selects for changes in testicular architecture and kinetics of germ cell development that are established early in postnatal development at the time of the first spermatogenic wave. The absolute and relative volumes of seminiferous tubules in the testis exhibit differences between species in agreement with their sperm competition levels and, similarly, the kinetics of germ cell development, as seen from the proportion of tubules with different germ cell types during postnatal development, are also associated with sperm competition levels.

Perhaps the most generally observed response to sperm competition is an increase in sperm numbers (Gomendio et al. 1998, Gómez Montoto et al. 2011) because more sperm enhance the chances of fertilization, as seen in the mouse (Robl \& Dziuk 1984) and other species (Birkhead \& Møller 1998, Gomendio et al. 1998). Thus, it is important to understand how males can increase sperm output under conditions of sperm competition. Adult males are known to invest in larger testes in relation to body mass when facing higher sperm competition levels (Harcourt et al. 1981, Hosken 1997, 1998, Stockley et al. 1997, Gomendio et al. 1998, Byrne et al. 2002). Recent studies have revealed that testis morphology and architecture may also be influenced by sperm competition (Lüpold et al. 2009b, 2011, Rowe \& Pruett-Jones 2011). Furthermore, the duration of spermatogenesis may be modified to increase sperm production under sperm competition, with higher relative testes mass associated with changes in the kinetics of spermatogenesis that would presumably generate sperm at faster rates (Wistuba et al. 2003, Luetjens et al. 2005, Ramm \& Stockley 2010).

We have used a group of closely related mouse species differing in sperm competition levels as revealed by testes mass relative to body mass. Values of body and testes masses of the males in this study, which are derived from natural populations but have been bred for a few generations under laboratory conditions, were similar to those recorded in natural populations (Frynta et al. 2009). Sperm competition in these species has favoured an increase in sperm numbers (quantity) in epididymal 


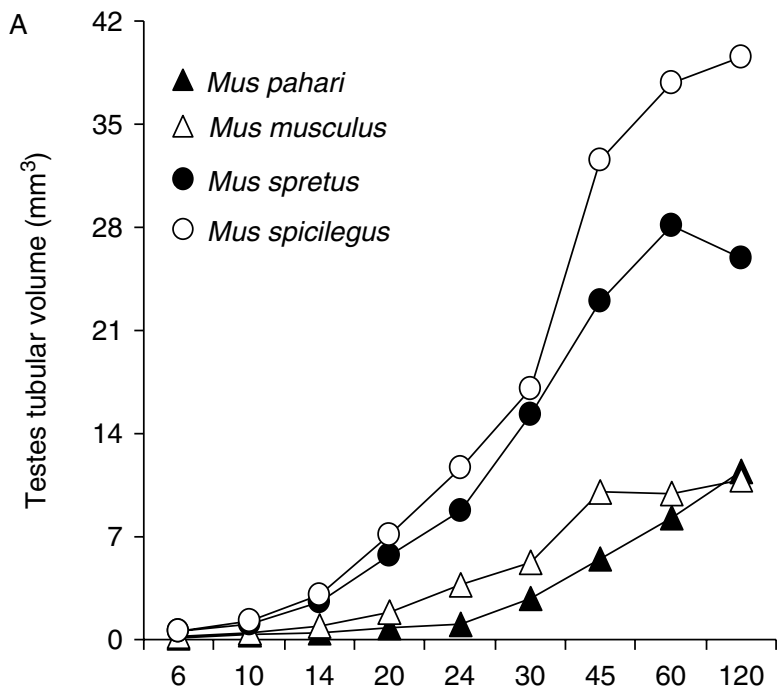

B

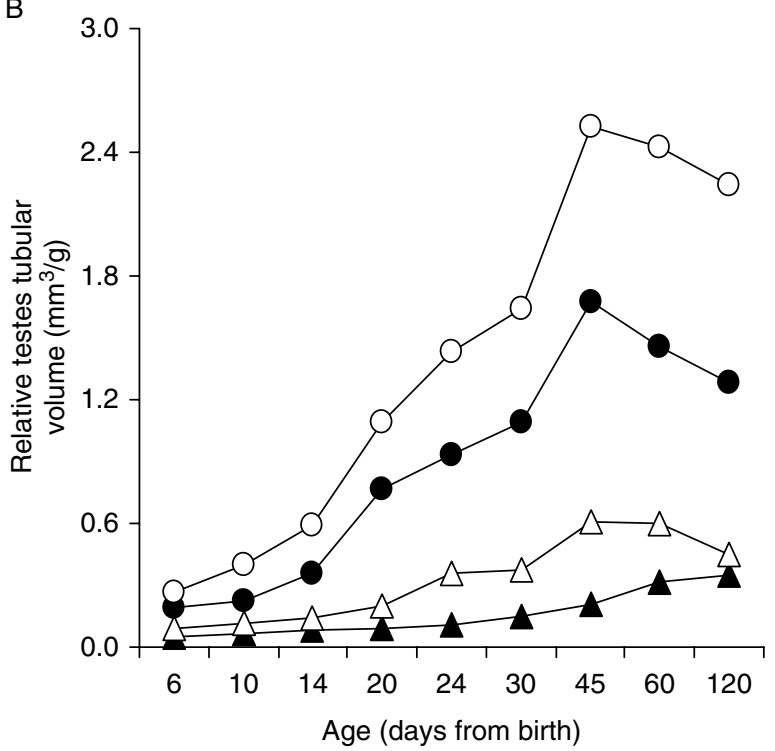

Figure 5 (A) Volume of testes occupied by seminiferous tubules and (B) relative volume occupied by seminiferous tubules in the testes of four mouse species (M. pahari, M. musculus, M. spretus, and M. spicilegus) at different times after birth.

reserves, and in sperm quality (percentages of motile, normal, and acrosome-intact spermatozoa; Gómez Montoto et al. 2011). Differences in sperm competition levels in these mouse species were also associated with functional sperm traits such as the proportion of sperm that undergo changes in preparation for fertilization (capacitation) and the percentage of spermatozoa that undergo exocytosis of the acrosome in response to a physiological ligand (Gomendio et al. 2006). In addition, these species showed fertilization success in competitive contexts that mirrored their levels of sperm competition (Martín-Coello et al. 2009). As a consequence, these mouse species were regarded as a suitable model to examine the differences in testicular morphology and kinetics of germ cell transitions during the establishment of spermatogenesis.

We detected clear differences between these species in postnatal changes in body mass (i.e. growth) and testes mass and, as a consequence, in their relative testes mass at different times after birth. Testes mass in relation to body mass showed differences between species that were evident after 14 days, with two groups clearly noticeable, one of $M$. pahari and M. musculus, with lowintermediate sperm competition levels, and another one of M. spretus and M. spicilegus, with intermediate-high levels of sperm competition. These differences remained thereafter. Thus, differences in absolute testes mass, and in testes mass relative to body mass, appear very early in postnatal development.

We also examined changes in measures (size) of different components of seminiferous tubules. There was an increase in dimensions and area throughout the period of postnatal development. An increase in seminiferous tubule cross-sectional area, and seminiferous epithelium height and area, was observed in all species beginning at 20 days postpartum, but the differences observed did not follow the pattern predicted from the levels of sperm competition of these species. These results suggest that there is no direct association between sperm competition levels and absolute measures of seminiferous tubules and they agree with those reported by Lüpold et al. (2009b) who also found differences between tubule dimensions in passerine birds, although such differences were not explained by relative testes mass or other indicators of female promiscuity such as a mating system.

Changes in the percentage of total seminiferous tubules in the testis, i.e. the proportion of testis area occupied by seminiferous tubules, could explain differences in sperm output. We reasoned that differential investments in sperm-producing machinery may become evident soon after spermatogenesis is switched on. We found that changes in the percentage of total seminiferous tubules varied considerably between species from the early stages after birth. It was lower for M. pahari, the species with the lowest relative testes mass, although values were not different for the other species throughout postnatal development, and therefore no clear association with sperm competition levels was seen. On the other hand, an association between the percentage of seminiferous tubules and sperm competition levels was seen among adult males and this agrees with recent studies in birds (Rowe \& Pruett-Jones 2011). We also reasoned that, rather than the percentage of area occupied by tubules, the overall proportion of testes volume occupied by seminiferous tubules would be more informative. This was indeed the case, because volume of testes occupied by seminiferous tubules ( $V_{\mathrm{TTb}}$; both absolute and relative to body mass) was different between species throughout postnatal development, and such differences were associated with the levels of sperm competition. It follows that testicular architecture is 

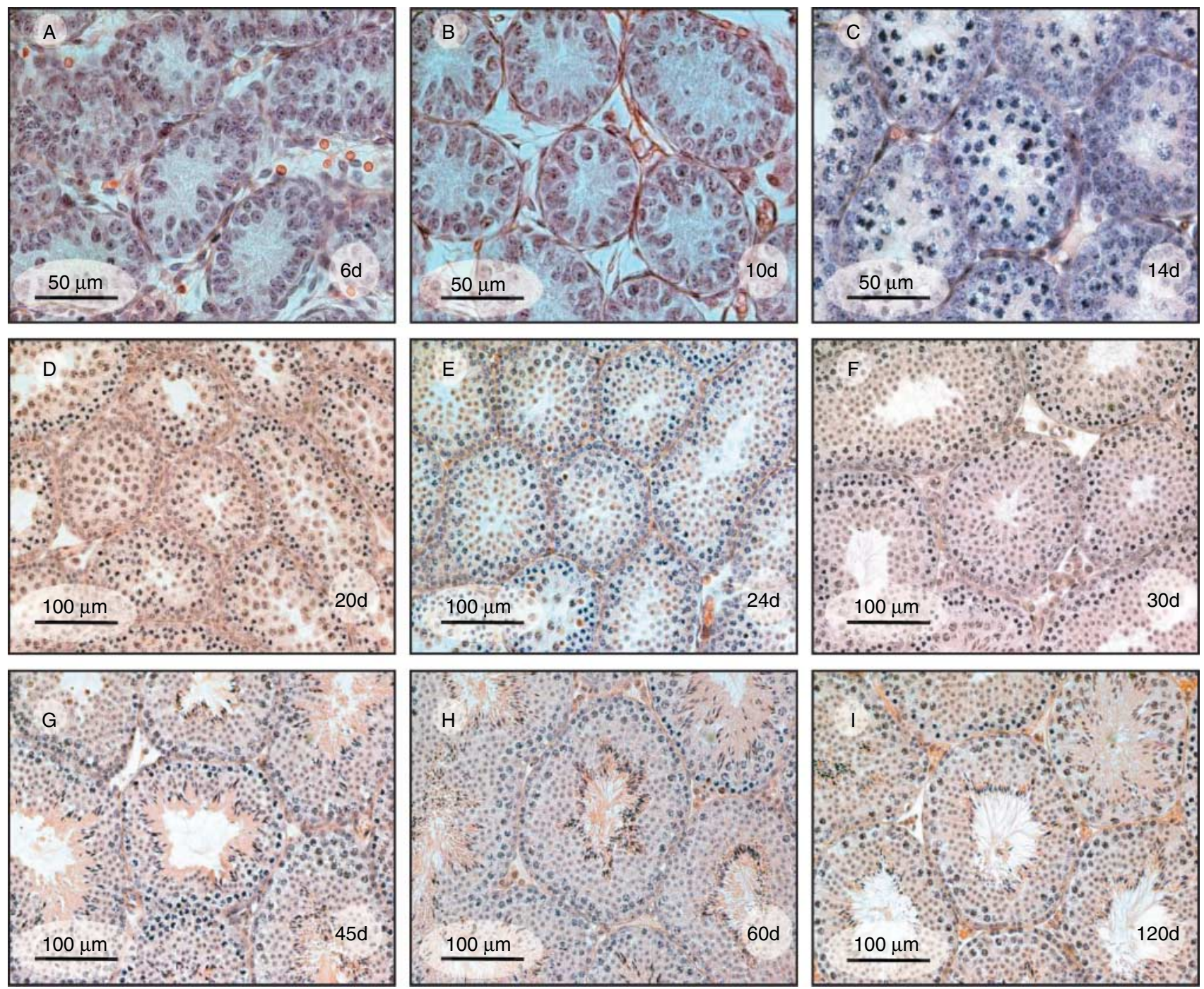

Figure 6 Histological cross-sections of seminiferous tubules of testes from Mus spicilegus from 6 days after birth until sexual maturity illustrating the first spermatogenic wave. (A) Section at 6 days postpartum: only Sertoli cells and spermatogonia are seen in the seminiferous tubules. (B) Ten days postpartum with only Sertoli cells and spermatogonia in the seminiferous tubules. (C) Fourteen days postpartum: more than half of the seminiferous tubules already contain spermatocytes. (D) Twenty days postpartum: the majority of the seminiferous tubules exhibit spermatocytes as the most advanced germ cell type but round spermatids are already present in some tubules. (E) Twenty-four days postpartum: seminiferous tubules with round spermatids are the predominant type in the testis followed by seminiferous tubules with spermatocytes. (F) Thirty days postpartum: elongating and elongated spermatids appear for the first time in the seminiferous tubules. (G) Forty-five days postpartum: around $90 \%$ of the seminiferous tubules in the testis contain round, elongating, or elongated spermatids as the most advanced germ cell type. (H) Sixty days after birth: structure of the testis is similar to that seen at 45 days. (I) One hundred and twenty days after birth: testis structure is similar to the one observed 45 days postpartum.

established early on during the first spermatogenic wave, with the volume of machinery assigned to sperm production following the levels of sperm competition. To the best of our knowledge, this is the first evidence identifying such a developmental pattern.

Finally, we also assessed the progression in the proportion of seminiferous tubules categorized according to the most advanced cell stage in the sequence of germinal epithelium differentiation. Prior studies in the laboratory mouse have revealed a precise timing of appearance of ever more differentiated cell stages at different times after birth until continuous spermatogenesis is established (Bellvé et al. 1977, Bellvé 1993, Borg et al. 2010). This first spermatogenic wave may be rather synchronous in some species (e.g. Djungarian hamster (Phodopus sungorus)), with the majority of the seminiferous tubules undergoing a parallel progression, or it may lack such synchrony (e.g. rat; Van Haaster \& De Rooij 1994). Interestingly, it appears that this first spermatogenic wave may be slightly shorter than that seen in adult animals, and such shortening seems to take place perhaps in the early days of postpartum development, before testicular descent (with the shortening perhaps due to a higher 

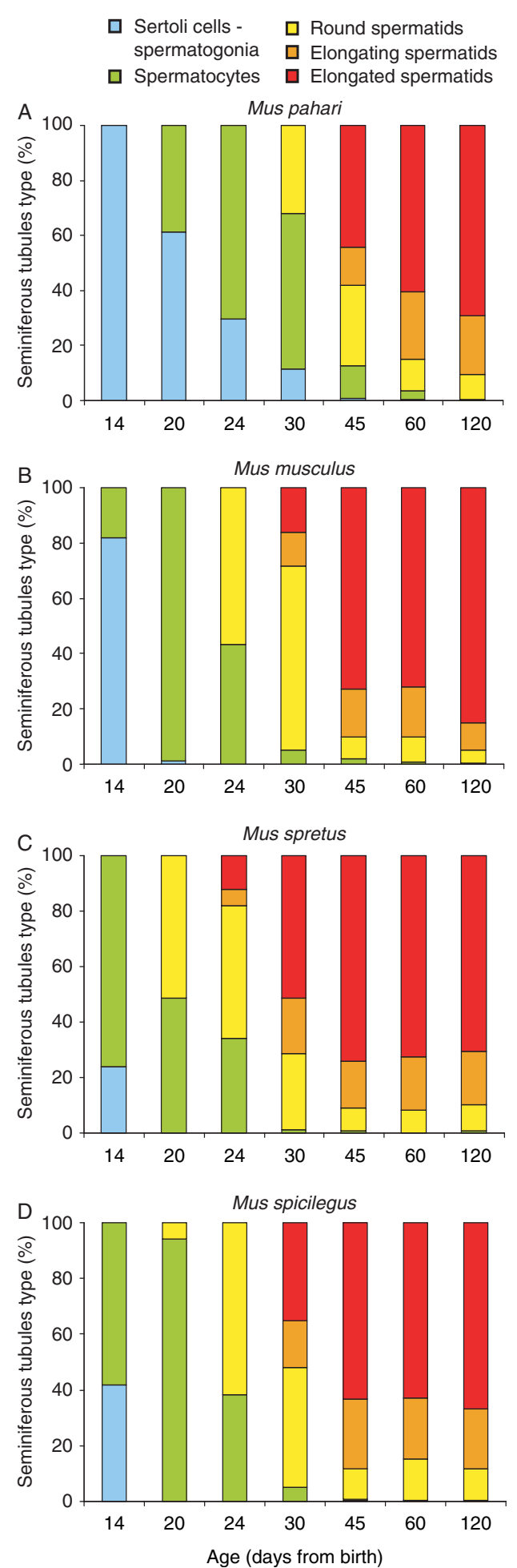

Figure 7 Changes in seminiferous tubules during postnatal development of four mouse species (M. pahari, M. musculus, M. spretus, and M. spicilegus). Each panel shows, for each species, the percentage of seminiferous tubules, according to the most advanced cell type in each tubule, at different times after birth. Cells identified were Sertoli cells and spermatogonia, spermatocytes, round spermatids, elongating spermatids, and elongated spermatids. intra-abdominal temperature; Kluin et al. 1982, Van Haaster \& De Rooij 1993). In all the species studied so far there is a clear association between the duration of the first spermatogenic wave and subsequent ones (Kluin et al. 1982, Van Haaster \& De Rooij 1993). In addition, the first wave has the same pattern of cellular associations observed in the adult male, as seen in various species (Kluin et al. 1982, Van Haaster \& De Rooij 1993). Furthermore, the morphology of the spermatogonia observed in immature mice during postnatal development is similar to that of adult spermatogonia (Drumond et al. 2011). The transit through the first spermatogonial phase seems to be the one exhibiting this shortening when compared to adults (Drumond et al. 2011), in agreement with the earlier studies (Kluin et al. 1982), whereas no shortening in the development of spermatocytes and/or spermatids was seen. Therefore, the use of this first spermatogenic wave to understand the kinetics of germ cell differentiation is reliable and well established.

Our study revealed important differences between species with regard to the onset and timing of the first spermatogenic wave. When the pattern of changes in this first spermatogenic wave of the different species was compared with their relative testes mass, a clear association between both was revealed, with the species showing the higher sperm competition levels exhibiting changes earlier than those in the other species.

We assessed this further by estimating the duration of the transition from spermatocytes to elongated spermatids in the first spermatogenic wave. This analysis revealed that species with lower levels of sperm competition (M. pahari and M. musculus) had a much slower transition (i.e. more days taken to move along the cell stages, which was about 35-40 days in these two species). In comparison, species with higher sperm competition levels (M. spretus and M. spicilegus) had a much faster transition time, which was estimated to be about 31 and 25 days respectively. These results agree well with data from laboratory mice (of M. m. musculus and M. m. domesticus descent) in which the total duration of spermatogenesis is about 35 days (Oakberg 1956, Hess \& França 2008). Our results also agree with the proposal by Ramm \& Stockley (2010) that species with higher sperm competition levels, with higher relative testes mass, have shorter cycles of the seminiferous epithelium (indicative of a shorter duration of spermatogenesis), thus allowing for an increase in sperm production rate. Thus, the study of the first wave of spermatogenesis in closely related species will represent an outstanding model for the characterization of gene expression, hormone regulation and local factor control during germ cell proliferation, meiosis, and postmeiotic differentiation under different levels of sperm competition.

In conclusion, this study reveals how developmental patterns during the first wave of spermatogenesis vary 

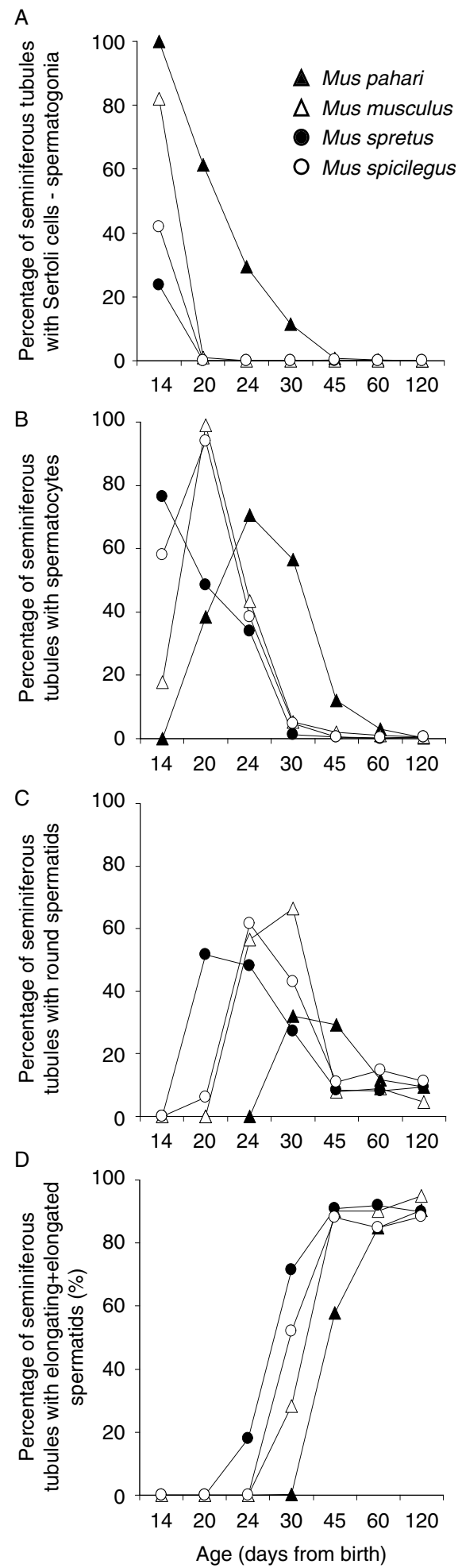

Figure 8 Comparison between four mouse species (M. pahari, M. musculus, M. spretus, and M. spicilegus) of postnatal changes in the seminiferous tubules. Each panel compares the timing of changes in different cell types for different species. Seminiferous tubules were classified according to the most advanced cell stage identified and the percentage of seminiferous tubules with (A) Sertoli cells-spermatogonias; (B) spermatocytes; (C) round spermatids and (D) elongating+elongated spermatids is shown. between species with different levels of sperm competition. These early differences in testicular architecture and kinetics of sperm formation are likely to be responsible for the differences observed at sexual maturity, which influence sperm production rates.

\section{Materials and Methods Animals and sample collection}

Males of M. pahari, M. musculus, M. spretus, and M. spicilegus were studied. Animals were born and maintained in our animal facilities where they were kept under standard laboratory conditions in environmentally controlled rooms at $20-24^{\circ} \mathrm{C}$, on a $1400 \mathrm{~h}$ light- $1000 \mathrm{~h}$ darkness photoperiod, and provided with food and water ad libitum. Males aged 6, 10, 14, 20, 24, $30,45,60$, and 120 days postpartum (day of birth was regarded as day 0 ) were sacrificed and were immediately weighed and dissected. For each species, sample size was three individuals for ages 6-60 days postpartum and six individuals for 120-dayold males. All animal handling was done following the Spanish Animal Protection Regulation RD1201/2005, which conforms to European Union Regulation 2003/65.

Testes were weighed and fixed in Bouin's solution during $24 \mathrm{~h}$, transferred to $70 \%$ ethanol and maintained in the latter solution until processed. Testes were embedded in paraffin, sectioned transversally (5 $\mu \mathrm{m}$ thickness), and stained with haematoxylin-eosin.

Images were taken using a digital camera (Digital Sight DS-5M, Nikon, Tokyo, Japan) and software for image capture (NIS-Elements F v.2.20, Nikon). Between five and 11 photographic images were taken from different and nonadjacent parts of one testis from each individual $(n=6.4 \pm 0.7$ images, mean \pm S.E.M.). Each image included a group of transversal sections of seminiferous tubules. Image sizes were $2560 \times 1920$ pixels, corresponding to $0.03 \mathrm{~mm}^{2}$ of the testis section, for males aged from 6 to 14 days, whereas the area was $0.1 \mathrm{~mm}^{2}$ of the testis section for males aged from 20 to 120 days. Images were captured from testis areas where round cross-sections of the seminiferous tubules were prevalent. Measures of seminiferous tubules were taken using ImageJ v.1.41 software (National Institutes of Health, Bethesda, MD, USA).

\section{Absolute measures and proportions of seminiferous tubules}

We obtained the following measures from the seminiferous tubule cross-sections (Fig. 2): a) the 'seminiferous tubule crosssectional area' $\left(\mu \mathrm{m}^{2}\right)$ was obtained by tracing the tubule's circumference. b) The 'seminiferous epithelium height' ( $\mu \mathrm{m})$ was obtained by measuring the height of the seminiferous epithelium in four different parts of each tubule and then calculating the mean value. c) The 'seminiferous tubule lumen area' $\left(\mu \mathrm{m}^{2}\right)$ resulted from measuring the length and width of the lumen in each tubule, and calculating the lumen area as the area of an ellipse $=\pi \times$ lumen length $/ 2$ (semi-major axis) $\times$ lumen width $/ 2$ (semi-minor axis). Finally, d) the 'seminiferous epithelium area in each tubule' $\left(\mu \mathrm{m}^{2}\right)$ was calculated by subtracting the lumen area from the seminiferous tubule cross-sectional area. 


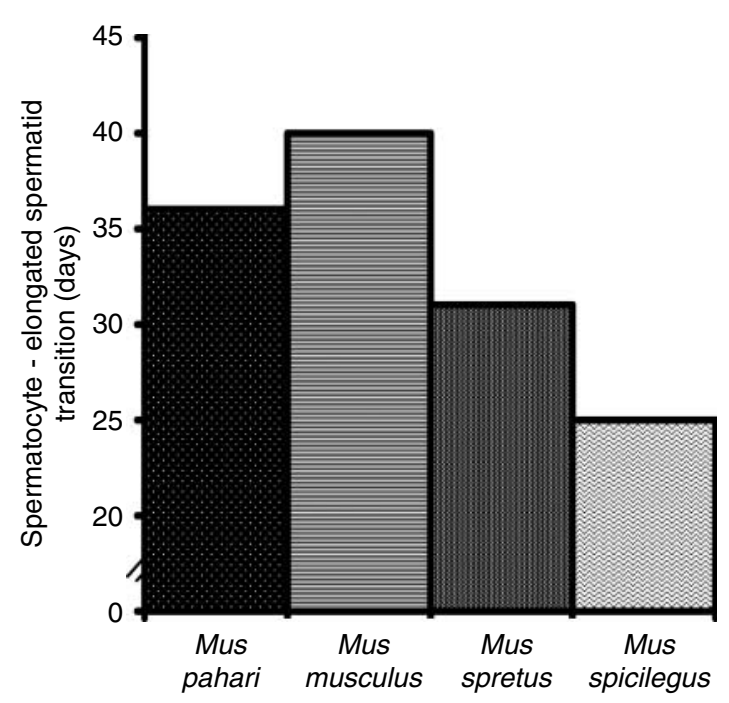

Figure 9 Transition time in days from spermatocytes to elongated spermatids in the seminiferous tubules of the four mouse species used in this study.

To calculate the proportions of seminiferous tubules and interstitial tissue, each photographic image (corresponding to 0.03 or $0.1 \mathrm{~mm}^{2}$ of the testis section) was measured to obtain the 'total seminiferous tubule cross-sectional area' $\left(\mu \mathrm{m}^{2}\right)$, which was the total area of the image represented by seminiferous tubules. This was done by tracing the circumference of cross-sections of all seminiferous tubules in the image (Fig. 2). Then, the 'percentage of total seminiferous tubules' was calculated as the proportion of the testis area occupied by seminiferous tubules. The 'percentage of interstitial tissue' was calculated as the proportion of testis area not occupied by seminiferous tubules, i.e. the difference between the image area and percentage of area occupied by seminiferous tubules. Using the values of these proportions for each photographic image we then obtained the values of these proportions for each male. Finally, using the values of each proportion for all males of the same age, we calculated the mean value for each age and species.

\section{Volumetric measures}

The testes volume $\left(V_{\mathrm{T}}, \mathrm{mm}^{3}\right)$ of each male was calculated by dividing testes mass by testes density of each species (L Gómez Montoto, M Gomendio and E R S Roldan, unpublished results). Then, the volumetric value of the variable 'percentage of total seminiferous tubules' was calculated assuming a uniform distribution of this testis component in the entire organ. Thus, 'volume of testes occupied by seminiferous tubules' $\left(V_{\mathrm{TTb}}, \mathrm{mm}^{3}\right)=$ $V_{\mathrm{T}} \times$ percentage of total seminiferous tubules/100. The value for this measure was calculated for each male and, subsequently, it was calculated for each age group for each species.

\section{Postnatal seminiferous tubule development}

The first wave of spermatogenesis was examined in sections from both testes of mice aged 14, 20, 24, 30, 45, and 60 days postpartum; testes sections of adult mice (120 days old) were also assessed. Earlier stages were not included in these analyses because at 6 and 10 days postpartum, cell types in one species (M. pahari) were not easily identified. Seminiferous tubules from the testes of each individual were examined to identify the germ cell types present. The earliest stage recognized comprised tubules containing only Sertoli cells-spermatogonia; spermatogonial types were not distinguished. Other cell types used to categorize seminiferous tubules were spermatocytes, round spermatids, elongating spermatids, and elongated spermatids. Each seminiferous tubule was categorized according to the most advanced cell type identified. Then, the proportion of tubules with each cell type (as the most advanced cell type) was calculated for each postnatal stage of development. The following categories were used to describe the seminiferous tubules: a) Sertoli cell-spermatogonia, b) spermatocytes (premeiosis), c) round spermatids (early spermiogenesis), and d) elongating spermatids and e) elongated spermatids (late spermiogenesis). Data were collected for each testis and means were calculated for each male (from both testes) and, subsequently, for each age group and species.

We estimated the time taken for the transition between some cell types in each species. This was done by taking into account the average time of appearance of the different cell types. We noted the earliest cell type that could be clearly identified in the tubules of all species (i.e. spermatocytes) and recorded the day when the maximum percentage of tubules with this cell type was found. Then, we identified the occurrence of the maximum percentage of tubules with round spermatids and, subsequently, of elongating spermatids. Finally, we noted the time point for each species when the percentage of elongated spermatids reached the highest point and remained elevated. Using these data we calculated the number of days for the different transitions.

\section{Statistical analyses}

A factorial ANOVA followed by Bonferroni's post-hoc tests for multiple comparisons was used to test differences in variables of testicular morphology (absolute measures, proportions, and volumetric measures) between mouse species with different levels of sperm competition at different days postpartum. A one-way ANOVA by groups (ages), also followed by Bonferroni's post-hoc tests for multiple comparisons, was used to detect differences in the previous variables within each age group between mouse species.

For data presentation in figures we calculated relative testes mass for each age group and species following Kenagy and Trombulak's formula for rodents $\left(Y=0.031 \cdot X^{0.77}\right.$, where $Y$ is predicted testes mass in grams for the observed body mass $X$; Kenagy \& Trombulak 1986). Relative testes mass was calculated as the ratio of observed testes mass to the predicted testes mass $Y$. Similarly, the relative volume of testes occupied by seminiferous tubules (relative $V_{\mathrm{TTb}}$ ) was calculated for each age group and species by dividing testes tubular volume ( $\left.V_{\mathrm{TTb}}\right)$ by body mass. Relative testes masses and relative $V_{\mathrm{TTb}}$ were not used in statistical analyses because they do not properly account for the allometric relationships between the variables (Tomkins \& Simmons 2002). 
All statistical analyses were conducted with SPSS v.17 (SPSS Inc., Chicago, IL, USA) and $P$ values were considered statistically significant at $\alpha<0.05$.

\section{Declaration of interest}

The authors declare that there is no conflict of interest that could be perceived as prejudicing the impartiality of the research reported.

\section{Funding}

This work was supported by the Spanish Ministry of Science and Innovation. L G Montoto and L Arregui were supported by predoctoral studentships from the Spanish Ministry of Education and Science. N M Sánchez was supported by the FINNOVA-I programme of the Comunidad de Madrid which is co-funded by the European Social Fund of the European Union.

\section{Acknowledgements}

We are deeply indebted to François Bonhomme and Annie Orth (Institut des Sciences de I'Evolution, CNRS-Université Montpellier 2) for facilitating the acquisition of wild mice. We are also grateful to Soledad Montalbán Iglesias and Óscar Javier Sánchez Sánchez from the Histology Service of the Centro Nacional de Biotecnología (CSIC) for their excellent work in the preparation of the histological testis sections and to Lluis Montoliu for the facilitating access to the Service. We thank the staff of our animal facilities for their help during this study.

\section{References}

Albert S, Ehmcke J, Wistuba J, Eildermann K, Behr R, Schlatt S \& Gromoll J 2010 Germ cell dynamics in the testis of the postnatal common marmoset monkey (Callithrix jacchus). Reproduction 140 733-742. (doi:10.1530/REP-10-0235)

Anway MD, Li Y, Ravindranath N, Dym M \& Griswold MD 2003 Expression of testicular germ cell genes identified by differential display analysis. Journal of Andrology 24 173-184.

Arregui L, Rathi R, Megee SO, Honaramooz A, Gomendio M, Roldan ERS \& Dobrinski I 2008 Xenografting of sheep testis tissue and isolated cells as a model for preservation of genetic material from endangered ungulates. Reproduction 136 85-93. (doi:10.1530/REP-07-0433)

Barakat B, O'Connor AE, Gold E, de Kretser DM \& Loveland KL 2008 Inhibin, activin, follistatin and FSH serum levels and testicular production are highly modulated during the first spermatogenic wave in mice. Reproduction 136 345-359. (doi:10.1530/REP-08-0140)

Bellvé AR 1993 Purification, culture, and fractionation of spermatogenic cells. Methods in Enzymology 225 84-113.

Bellvé AR, Cavicchia JC, Millette CF, O'Brien DA, Bhatnagar YM \& Dym M 1977 Spermatogenic cells of the prepuberal mouse. Isolation and morphological characterization. Journal of Cell Biology 74 68-85. (doi:10.1083/jcb.74.1.68)

Birkhead TR \& Møller AP 1998 Sperm Competition and Sexual Selection, San Diego: Academic Press.

Birkhead TR, Martinez JG, Burke T \& Froman DP 1999 Sperm mobility determines the outcome of sperm competition in the domestic fowl. Proceedings of the Royal Society of London B 266 1759-1764. (doi:10. 1098/rspb.1999.0843)

Birkhead TR, Hosken DJ \& Pitnick S 2009 Sperm Biology. An Evolutionary Perspective, Burlington, MA: Academic Press.
Borg CL, Wolski KM, Gibbs GM \& O'Bryan MK 2010 Phenotyping male infertility in the mouse: how to get the most out of a 'non-performer'. Human Reproduction Update 16 205-224. (doi:10.1093/humupd/ dmp032)

Breed WG 1982 Morphological variation in the testes and accessory sex organs of Australian rodents in the genera Pseudomys and Notomys. Journal of Reproduction and Fertility 66 607-613. (doi:10.1530/jrf.0. 0660607)

Byrne PG, Roberts JD \& Simmons LW 2002 Sperm competition selects for increased testes mass in Australian frogs. Journal of Evolutionary Biology 15 347-355. (doi:10.1046/j.1420-9101.2002.00409.x)

Cao SF, Li D, Yuan Q, Guan X \& Xu C 2008 Spatial and temporal expression of $c$-mos in mouse testis during postnatal development. Asian Journal of Andrology 10 277-285. (doi:10.1111/j.1745-7262.2008.00324.x)

Clermont Y 1972 Kinetics of spermatogenesis in mammals: seminiferous epithelium cycle and spermatogonial renewal. Physiological Reviews $\mathbf{5 2}$ 198-236.

De Rooij D \& Russell LD 2000 All you wanted to know about spermatogonia but were afraid to ask. Journal of Andrology 21 776-798.

Drumond AL, Meistrich ML \& Chiarini-Garcia H 2011 Spermatogonial morphology and kinetics during testis development in mice: a highresolution light microscopy approach. Reproduction 142 145-155. (doi:10.1530/REP-10-0431)

Ehmcke J, Wistuba J \& Schlatt S 2006 Spermatogonial stem cells: questions, models and perspectives. Human Reproduction Update 12 275-282. (doi:10.1093/humupd/dmk001)

Firman RC \& Simmons LW 2008 The frequency of multiple paternity predicts variation in testes size among island populations of house mice. Journal of Evolutionary Biology 21 1524-1533. (doi:10.1111/j.14209101.2008.01612.x)

Firman RC \& Simmons LW 2010 Experimental evolution of sperm quality via postcopulatory sexual selection in house mice. Evolution 64 1245-1256. (doi:10.1111/j.1558-5646.2009.00894.x)

Fitzpatrick JL, Montgomerie R, Desjardins JK, Stiver KA, Kolm N \& Balshine S 2009 Female promiscuity promotes the evolution of faster sperm in cichlid fishes. PNAS 106 1128-1132. (doi:10.1073/pnas. 0809990106)

Frynta D, Slábová M \& Vohralík V 2009 Why do male house mice have such small testes? Zoological Science 26 17-23. (doi:10.2108/zsj.26.17)

Fujii-Hanamoto H, Matsubayashi K, Nakano M, Kusunoki H \& Enomoto T 2011 A comparative study on testicular microstructure and relative sperm production in gorillas, chimpanzees, and orangutans. American Journal of Primatology 73 570-577. (doi:10.1002/ajp.20930)

García-González F \& Simmons LW 2005 Sperm viability matters in insect sperm competition. Current Biology 15 271-275. (doi:10.1016/j.cub. 2005.01.032)

Gomendio M \& Roldan ERS 1991 Sperm competition influences sperm size in mammals. Proceedings of the Royal Society of London B 243 181-185. (doi:10.1098/rspb.1991.0029)

Gomendio M \& Roldan ERS 2008 Implications of diversity in sperm size and function for sperm competition and fertility. International Journal of Developmental Biology 52 439-447. (doi:10.1387/ijdb. $082595 \mathrm{mg}$ )

Gomendio M, Harcourt AH \& Roldan ERS 1998 Sperm competition in mammals. In Sperm Competition and Sexual Selection, pp 667-755. Eds TR Birkhead \& AP Møller. San Diego: Academic Press.

Gomendio M, Martín-Coello J, Crespo C, Magaña C \& Roldan ERS 2006 Sperm competition enhances functional capacity of mammalian spermatozoa. PNAS 103 15113-15117. (doi:10.1073/pnas. 0605795103)

Gomendio M, Malo AF, Garde J \& Roldan ERS 2007 Sperm traits and male fertility in natural populations. Reproduction 134 19-29. (doi:10.1530/ REP-07-0143)

Gomendio M, Tourmente M \& Roldan ERS 2011 Why mammalian lineages respond differently to sexual selection: metabolic rate constrains the evolution of sperm size. Proceedings of the Royal Society of London B 278 3135-3141. (doi:10.1098/rspb.2011.0275)

Gómez Montoto L, Magaña C, Tourmente M, Martín-Coello J, Crespo C, Luque-Larena IJ, Gomendio M \& Roldan ERS 2011 Sperm competition, sperm numbers and sperm quality in Muroid rodents. PLOS ONE 6 e18173. (doi:10.1371/journal.pone.0018173) 
Hansen MA, Nielsen JE, Tanaka M, Almstrup K, Skakkebaek NE \& Leffers H 2006 Identification and expression profiling of 10 novel spermatid expressed CYPT genes. Molecular Reproduction and Development 73 568-579. (doi:10.1002/mrd.20463)

Harcourt AH, Harvey PH, Larson SG \& Short RV 1981 Testis weight, bodyweight and breeding system in primates. Nature 293 55-57. (doi:10. 1038/293055a0)

Hermo L, Pelletier RM, Cyr DC \& Smith CE 2010 Surfing the wave, cycle, life history, and genes/proteins expressed by testicular germ cells. Part 1: Background to spermatogenesis, spermatogonia, and spermatocytes. Microscopy Research and Technique 73 243-278. (doi:10.1002/jemt. 20783)

Hess RA \& França LR 2008 Spermatogenesis and cycle of the seminiferous epithelium. In Molecular Mechanisms in Spermatogenesis, pp 1-15. Ed. CY Cheng. Austin, TX: Landes Bioscience/Springer Science+Business Media.

Hosken DJ 1997 Sperm competition in bats. Proceedings of the Royal Society of London B 264 385-392. (doi:10.1098/rspb.1997.0055)

Hosken DJ 1998 Testes mass in megachiropteran bats varies in accordance with sperm competition theory. Behavioral Ecology and Sociobiology 44 169-177. (doi:10.1007/s002650050529)

Hosken DJ \& Ward PI 2001 Experimental evidence for testis size evolution via sperm competition. Ecology Letters 4 10-13. (doi:10.1046/j.14610248.2001.00198.x)

Hunter FM \& Birkhead TR 2002 Sperm viability and sperm competition in insects. Current Biology 12 121-123. (doi:10.1016/S0960-9822(01) 00647-9)

Itman C \& Loveland KL 2008 SMAD expression in the testis: an insight into BMP regulation of spermatogenesis. Developmental Dynamics 237 97-111. (doi:10.1002/dvdy.21401)

Jahnukainen K, Chrysis D, Hou M, Parvinen M, Eksborg S \& Söder O 2004 Increased apoptosis occurring during the first wave of spermatogenesis is stage-specific and primarily affects midpachytene spermatocytes in the rat testis. Biology of Reproduction 70 290-296. (doi:10.1095/biolreprod. 103.018390)

Johnson L 1995 Efficiency of spermatogenesis. Microscopy Research and Technique 32 385-422. (doi:10.1002/jemt.1070320504)

Johnson L 2000 Efficiency of spermatogenesis: a comparative approach. Animal Reproduction Science 60-61 471-480. (doi:10.1016/S03784320(00)00108-1)

Kenagy GJ \& Trombulak SC 1986 Size and function of mammalian testes in relation to body size. Journal of Mammalogy 67 1-22. (doi:10.2307/ 1380997)

Kerr JB, Loveland KL, O'Bryan MK \& de Kretser DM 2006 Cytology of the testis and intrinsic control mechanisms. In Knobil and Neill's Physiology of Reproduction, pp 827-947. Ed. JD Neill. Amsterdam: Elsevier.

Kluin PM, Kramer MF \& De Rooij DG 1982 Spermatogenesis in the immature mouse proceeds faster than in the adult. International Journal of Andrology 5 282-294. (doi:10.1111/j.1365-2605.1982. tb00257.x)

Lahn BT, Tang ZL, Zhou J, Barndt RJ, Parvinen M, Allis CD \& Page DC 2002 Previously uncharacterized histone acetyltransferases implicated in mammalian spermatogenesis. PNAS 99 8707-8712. (doi:10.1073/ pnas.082248899)

Luetjens CM, Weinbauer GF \& Wistuba J 2005 Primate spermatogenesis: new insights into comparative testicular organisation, spermatogenic efficiency and endocrine control. Biological Reviews 80 475-488. (doi:10.1017/S1464793105006755)

Lüpold S, Calhim S, Immler S \& Birkhead TR 2009a Sperm morphology and sperm velocity in passerine birds. Proceedings of the Royal Society of London B 276 1175-1181. (doi:10.1098/rspb.2008.1645)

Lüpold S, Linz GM, Rivers JW, Westneat DF \& Birkhead TR 2009b Sperm competition selects beyond relative testes size in birds. Evolution $\mathbf{6 3}$ 391-402. (doi:10.1111/j.1558-5646.2008.00571.x)

Lüpold S, Wistuba J, Damm O, Rivers JW \& Birkhead TR 2011 Sperm competition leads to functional adaptations in avian testes to maximize sperm quantity and quality. Reproduction 141 595-605. (doi:10.1530/ REP-10-0501)

Martín-Coello J, Benavent-Corai J, Roldan ERS \& Gomendio M 2009 Sperm competition promotes asymmetries in reproductive barriers between closely related species. Evolution 63 613-623. (doi:10.1111/j.15585646.2008.00585.x)
Mithraprabhu S, Mendis S, Meachem SJ, Tubino L, Matzuk MM, Brown CW \& Loveland KL 2010 Activin bioactivity affects germ cell differentiation in the postnatal mouse testis in vivo. Biology of Reproduction 82 980-990. (doi:10.1095/biolreprod.109.079855)

Møller AP 1988 Ejaculate quality, testes size and sperm competition in primates. Journal of Human Evolution 17 479-488. (doi:10.1016/00472484(88)90037-1)

Møller AP 1989 Ejaculate quality, testes size and sperm production in mammals. Functional Ecology 3 91-96. (doi:10.2307/2389679)

Oakberg EF 1956 Duration of spermatogenesis in the mouse and timing of stages of the cycle of the seminiferous epithelium. American Journal of Anatomy 99 507-516. (doi:10.1002/aja.1000990307)

Oka A, Mita A, Takada Y, Koseki H \& Shiroishi T 2010 Reproductive isolation in hybrid mice due to spermatogenesis defects at three meiotic stages. Genetics 186 339-351. (doi:10.1534/genetics.110.118976)

Parker GA 1970 Sperm competition and its evolutionary consequences in insects. Biological Reviews 45 525-567. (doi:10.1111/j.1469-185X. 1970.tb01176.x)

Peirce EJ \& Breed WG 1987 Cytological organization of the seminiferous epithelium in the Australian rodents Pseudomys australis and Notomys alexis. Journal of Reproduction and Fertility 80 91-103. (doi:10.1530/jrf. 0.0800091)

Peirce EJ \& Breed WG 1990 Organization of testicular interstitial tissue of an Australian rodent, the spinifex hopping mouse, Notomys alexis. Cell and Tissue Research 260 469-477. (doi:10.1007/BF00297226)

Pitnick S, Miller GT, Reagan J \& Holland B 2001 Males' evolutionary responses to experimental removal of sexual selection. Proceedings of the Royal Society of London B 268 1071-1080. (doi:10.1098/rspb.2001. 1621)

Ramm SA \& Stockley P 2010 Sperm competition and sperm length influence the rate of mammalian spermatogenesis. Biology Letters 6 219-221. (doi:10.1098/rsbl.2009.0635)

Robl JM \& Dziuk PJ 1984 Influence of the concentration of sperm on the percentage of eggs fertilized for three strains of mice. Gamete Research 10 415-422. (doi:10.1002/mrd.1120100407)

Rowe M \& Pruett-Jones S 2011 Sperm competition selects for sperm quantity and quality in the Australian maluridae. PLOS ONE 6 e15720. (doi:10.1371/journal.pone.0015720)

Russell L, Ettlin RA, Hikim APS \& Clegg ED 1990 Histological and Histopathological Evaluation of the Testis, Clearwater, FL: Cache River Press.

Schultz AH 1938 The relative weight of the testes in primates. Anatomical Record 72 387-394. (doi:10.1002/ar.1090720310)

Setchell BP \& Breed WG 2006 Anatomy, vasculature, and innervation of the male reproductive tract. In Knobil and Neill's Physiology of Reproduction, pp 771-825. Ed. JD Neill. Amsterdam: Elsevier.

Simmons LW 2001 Sperm Competition and its Evolutionary Consequences in Insects, Princeton: Princeton University Press.

Soulsbury CD 2010 Genetic patterns of paternity and testes size in mammals. PLoS ONE 5 A152-A157. (doi:10.1371/journal.pone.0009581)

Stockley P, Gage MJG, Parker GA \& Moller AP 1997 Sperm competition in fishes: the evolution of testis size and ejaculate characteristics. American Naturalist 149 933-954. (doi:10.1086/286031)

Tanaka H, Hirose M, Tokuhiro K, Tainaka H, Miyagawa Y, Tsujimura A, Okuyama A \& Nishimune Y 2007 Molecular biological features of male germ cell differentiation. Reproductive Medicine and Biology 6 1-9. (doi:10.1111/j.1447-0578.2007.00158.x)

Tomkins JL \& Simmons LW 2002 Measuring relative investment: a case study of testes investment in species with alternative male reproductive tactics. Animal Behaviour 63 1009-1016. (doi:10.1006/anbe.2001. 1994)

Tourmente M, Gomendio M \& Roldan ERS 2011 a Sperm competition and the evolution of sperm design in mammals. BMC Evolutionary Biology 11 12. (doi:10.1186/1471-2148-11-12)

Tourmente M, Gomendio M \& Roldan ERS 2011b Mass-specific metabolic rate and sperm competition determine sperm size in marsupial mammals. PLOS ONE 6 e21244. (doi:10.1371/journal.pone. 0021244)

Van Haaster LH \& De Rooij DG 1993 Spermatogenesis is accelerated in the immature Djungarian and Chinese hamster and rat. Biology of Reproduction 49 1229-1235. (doi:10.1095/biolreprod49.6.1229) 
Van Haaster LH \& De Rooij DG 1994 Partial synchronization of spermatogenesis in the immature Djungarian hamster, but not in the immature Wistar rat. Journal of Reproduction and Fertility 101 321-326. (doi:10.1530/jrf.0.1010321)

Wistuba J, Schrod A, Greve B, Hodges JK, Aslam H, Weinbauer GF \& Luetjens CM 2003 Organization of seminiferous epithelium in primates: relationship to spermatogenic efficiency, phylogeny, and mating system. Biology of Reproduction 69 582-591. (doi:10.1095/biolreprod.103.015925)

Wrobel G \& Primig M 2005 Mammalian male germ cells are fertile ground for expression profiling of sexual reproduction. Reproduction 129 1-7. (doi:10.1530/rep.1.00408)
Zeng W, Avelar GF, Rathi R, França LR \& Dobrinski I 2006 The length of the spermatogenic cycle is conserved in porcine and ovine testis xenografts. Journal of Andrology 27 527-533. (doi:10.2164/jandrol. 05143)

Received 5 July 2011

First decision 24 August 2011

Revised manuscript received 9 December 2011

Accepted 20 December 2011 